\title{
Film adhesion in amorphous silicon solar cells
}

\author{
A R M YUSOFF*, M N SYAHRUL and K HENKEL \\ Malaysia Energy Centre, 8th Floor, North Wing, Sapura @ Mines, 7, Jalan Tasik, The Mines Resort City, \\ 43300 Seri Kembangan, Selangor Darul Ehsan
}

MS received 11 April 2007

\begin{abstract}
A major issue encountered during fabrication of triple junction a-Si solar cells on polyimide substrates is the adhesion of the solar cell thin films to the substrates. Here, we present our study of film adhesion in amorphous silicon solar cells made on different polyimide substrates (Kapton VN, Upilex-S and Gouldflex), and the effect of tie coats on film adhesion.
\end{abstract}

Keywords. Film adhesion; different polyimide substrates; amorphous silicon.

\section{Introduction}

Amorphous silicon ( $a-\mathrm{Si}$ ) based solar cells are desirable for space applications when fabricated on lightweight and flexible substrates. Being amorphous, $a-\mathrm{Si}$ is inherently more flexible than crystalline or polycrystalline materials, as well as radiation resistant (Kuendig et al 2000). While $a$-Si based flexible cells may be fabricated on thin metal substrates, plastic substrates have the advantage of being insulating, which allows monolithic cell interconnection. Polyimides, with their flexibility, mechanical strength and resistance to temperatures in excess of $400^{\circ} \mathrm{C}$ are a good choice of plastic substrate for the fabrication of flexible triple junction, amorphous silicon solar cells.

At the Malaysia Energy Centre (MEC), we fabricated triple junction amorphous silicon solar cells (up to $12.7 \%$ efficiency (Wang et al 2002)) and laser-interconnected modules on steel, glass and polyimide substrates. A major issue encountered is the adhesion of thin film solar cells on polyimide substrates. We evaluated different polyimide and polyimide-based substrates to determine their suitability for $a$-Si cell fabrication, from the point of view of film adhesion. The materials evaluated were Kapton VN, Kapton HN, Kapton E, Upilex-S and Gouldflex.

\section{Experimental}

Four different types of polyimide films (Kapton E, Kapton $\mathrm{HN}$, Kapton VN and Upilex-S) were heated in vacuum to check for outgassing. Out of the four polyimides, Kapton$\mathrm{E}$ was found to have a considerable amount of outgassing in the test. Kapton HN, VN and Upilex-S showed an acceptable amount of outgassing. Figure 1 shows the observed pre-

\footnotetext{
*Author for correspondence (abdrashid_4@yahoo.com)
}

ssure rises for (i) $125 \mathrm{~mm}$ thick Kapton VN and (ii) $125 \mathrm{~mm}$ thick Upilex-S. Triple junction amorphous silicon cells were fabricated on Kapton VN and Upilex-S for further study.

\subsection{Upilex-S}

An aluminum/zinc-oxide back-reflector was made by RF sputtering on $4^{\prime \prime} \times 4^{\prime \prime}, 125$ micron thick Upilex-S sub-
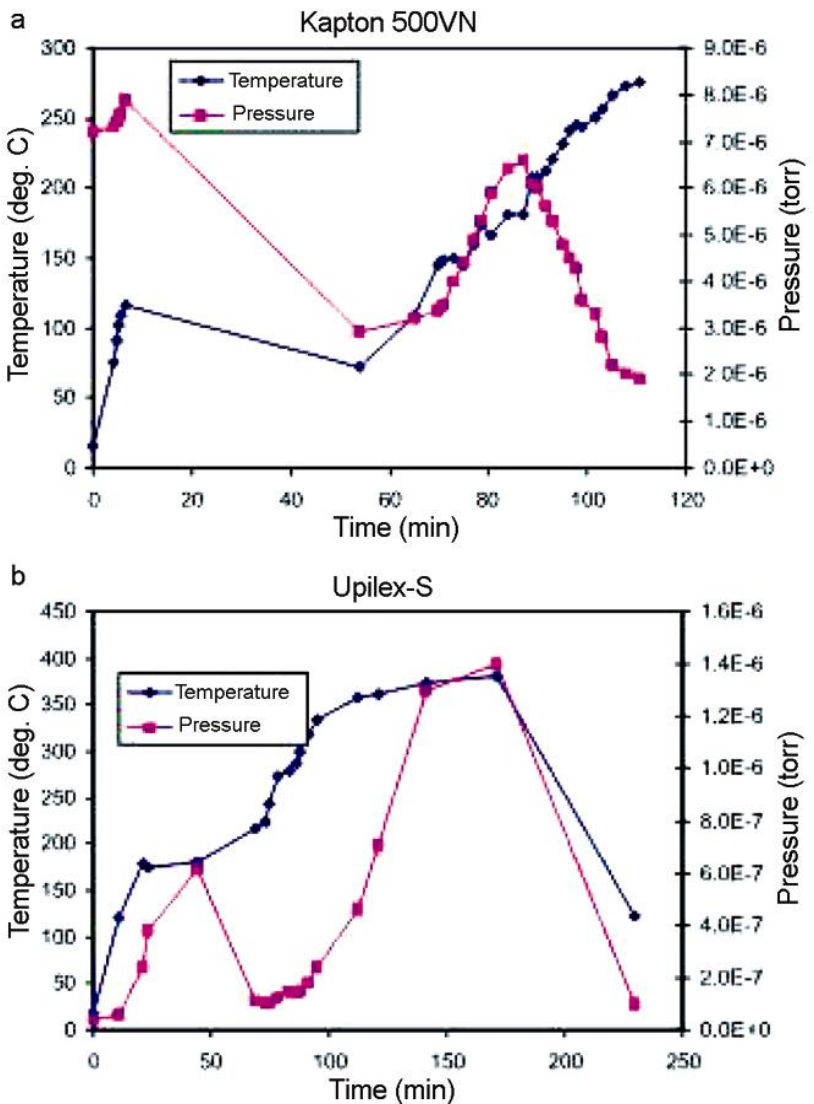

Figure 1. Outgassing from (a) Kapton VN and (b) Upilex-S. 
strate. A triple junction amorphous silicon cell was deposited on half of this back reflector. This portion of the sample showed severe cracking and delamination minutes after deposition (see figure 2). A few days after deposition, the portion without $a$-Si also developed cracks.

\subsection{Kapton $V N$}

An $\mathrm{Al} / \mathrm{ZnO}$ back reflector was also prepared on 125 micron thick Kapton VN, and a triple junction amorphous silicon cell was deposited on this. This cell remained in tact for over a week. However, it developed cracks when immersed in water for cleaning, probably due to thermal stress caused by sudden change in temperature upon immersion.

This experiment suggested that Kapton VN might be a better choice of substrate as compared to Upilex-S, from the point of view of film adhesion.

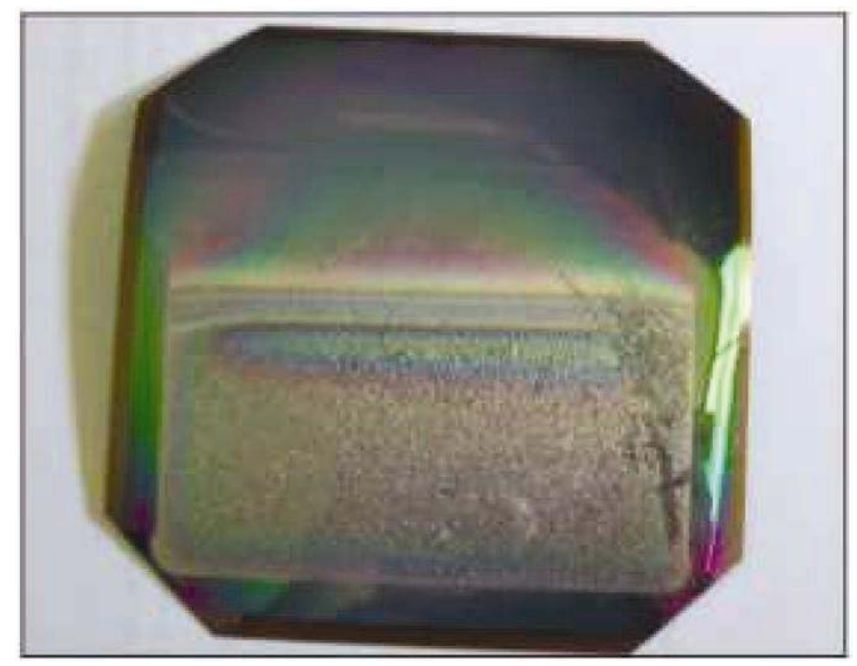

Figure 2. Back reflector on Upilex-S with $a$-Si triple cell on bottom, showing peeling.

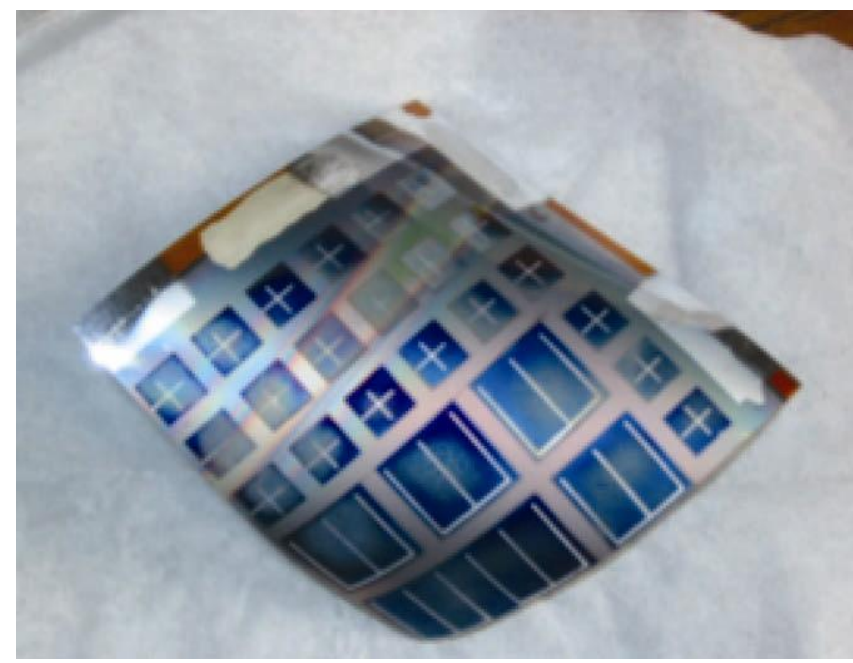

Figure 3. Triple junction $a$-Si cells on Mo-coated Kapton VN.
In both cases, the film delamination was at the back reflector/polyimide interface. A likely cause of the cracking/peeling is internal stress in the back reflector layers. The reason that Kapton performed better may be due to its lower bulk modulus (400 kpsi) as compared to Upilex$\mathrm{S}$ (1200 kpsi). A lower bulk modulus material may be able to better relieve stress through expansion.

\subsection{Tie-coats}

Although Kapton $500 \mathrm{VN}$ showed promise as a substrate material for flexible $a$-Si cells, $\mathrm{Al} / \mathrm{ZnO}$ back reflector films showed imperfect adhesion to it. We, therefore, evaluated various intermediate layers (tie-coats) to see if adhesion could be improved.

Certain transition metals are known to have excellent adhesion to glass and other substrate materials. For example, chromium and nickel alloys are used as tie coats to promote the adhesion of copper to polyimides (Sallo 1985; Bergkessel et al 2000). We evaluated chromium, molybdenum and zinc oxide as tie coats with our standard $\mathrm{Al} / \mathrm{ZnO}$ back-reflectors. We also evaluated nickel as a tiecoat for a $\mathrm{Ag} / \mathrm{ZnO}$ based back reflector. The procedure for evaluating the tie-coats was identical in all cases. We sputtered the tie-coat material onto a 4 " $\times 4$ " square of Kapton VN, then deposited the metal ( $\mathrm{Al}$ or $\mathrm{Ag}$ )/ZnO back reflector. A triple junction amorphous silicon solar cell was then deposited by PECVD on this coated substrate.

The triple-junction $a$-Si cell with chromium tie-coat and $\mathrm{Al} / \mathrm{ZnO}$ back reflector showed no signs of peeling or cracking after several immersions in water, and after several weeks, indicating that the $\mathrm{Cr}$ tie-coat did, in fact, promote

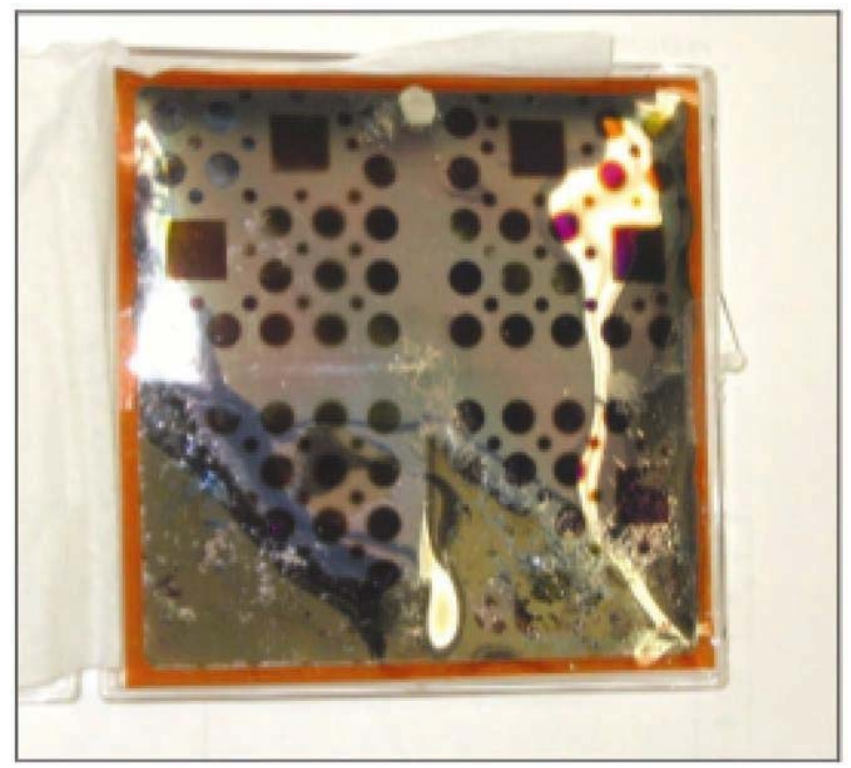

Figure 4. Effect of nickel (top half), chromium (lower left) and molybdenum (lower right) tie coats on adhesion of an $\mathrm{Ag} / \mathrm{ZnO}$ back reflector to Kapton VN. 


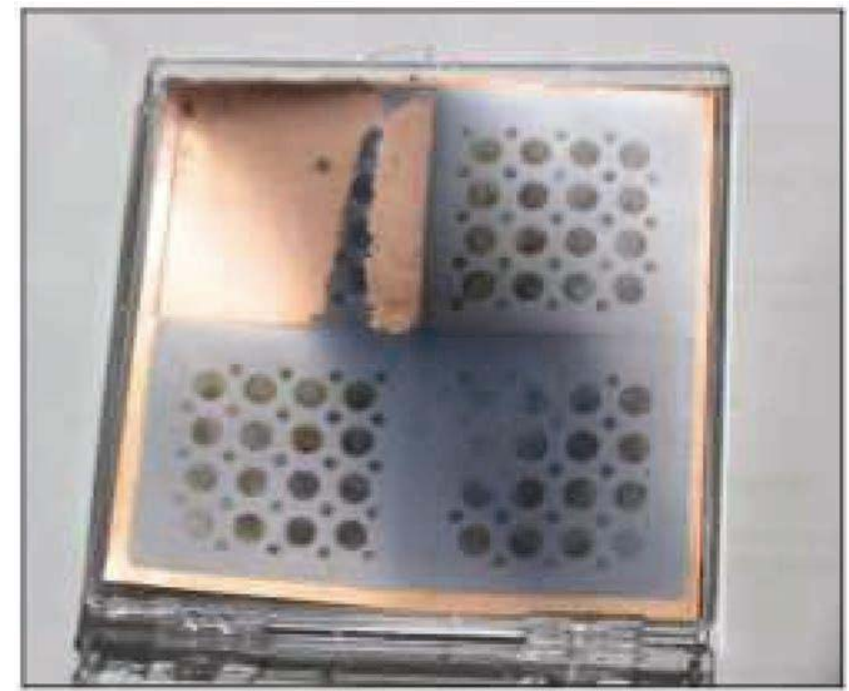

Figure 5. Single junction $a$-Si cells on Gouldflex.

adhesion. A similar effect was observed with a tie-coat of molybdenum. There was no cracking or peeling observed (see figure 3). We also evaluated a tie-coat made from zinc oxide deposited by RF sputtering. Back reflectors and a triple junction $a$-Si cells were then fabricated on this substrate. This tie-coat also promoted adhesion, there being no cracking or peeling of the sample after thermal cycling or immersion in water.

Since silver can be a superior choice of reflective material as compared to aluminum, we also evaluated the adhesion promoting properties of chromium, molybdenum and nickel on a $\mathrm{Ag} / \mathrm{ZnO}$ back reflector made on Kapton VN. Two quadrants of a $4 " \times 4$ " sample were sputter-coated with nickel, and the other two were coated with chromium and molybdenum. The $\mathrm{Ag} / \mathrm{ZnO}$ back reflector was made by RF sputtering. A triple-junction $a$-Si cell was deposited by PECVD. The portions on $\mathrm{Cr}$ and Mo showed severe delamination of the back-reflector and $a$-Si layers almost immediately after $a$-Si deposition. In contrast, the portion with the nickel tie-coat remained stable (see figure 4 for a photograph of the sample).

\subsection{Gouldflex}

Copper-coated Kapton material (Gouldflex) was procured from Flextronics (Johor, Malaysia) and a single $n-i-p$ amorphous silicon solar cell fabricated on this material, after verifying that the outgassing from the material was not excessive. The film we tested consisted of a Kapton base with a sputtered chromium tie coat and electrodeposited copper layers. Since copper is known to be a fast diffuser in silicon, three quarters of the copper were coated with aluminum or/and zinc oxide before amorphous silicon deposition. Thus, we had four combinations: $\mathrm{Cu}, \mathrm{Cu} / \mathrm{Al}$, $\mathrm{Cu} / \mathrm{ZnO}$ and $\mathrm{Cu} / \mathrm{Al} / \mathrm{ZnO}$. The $a-\mathrm{Si}$ film on bare $\mathrm{Cu}$ peeled off at the $\mathrm{Cu} / a$-Si interface (see figure 5 ), and cells on the other three quarters of this sample showed extremely poor performance. It is likely that the copper diffused into $a-\mathrm{Si}$, causing shunting and defects. We have, therefore, eliminated this material as a candidate for the triple junction flexible cell substrate.

\section{Conclusions}

We found that Kapton VN is a suitable substrate material for the fabrication of amorphous silicon solar cells. However, adhesion of back reflector and $a$-Si layers to Kapton VN is marginal unless an intermediate tie-coat layer is employed. We found that tie coats made from chromium, molybdenum and zinc oxide do promote adhesion of aluminum/zinc-oxide back-reflector layers to the Kapton substrate. Triple junction amorphous silicon cells were fabricated on these tie-coated substrates and were found to have good adhesion and conversion efficiencies. We also found that a nickel tie coat performs better than one made from chromium or molybdenum, if a silver reflective layer is used instead of aluminum. Amorphous silicon cells were also fabricated on commercially available coppercoated polyimide, but these were found to have poor performance, possibly due to diffusion of copper into the cells.

In conclusion, we have identified chromium, nickel, molybdenum and zinc oxide as suitable tie-coat materials. These tie coats have enabled us to fabricate triple junction amorphous silicon solar cells and interconnected sub-modules on polyimide substrates.

\section{Acknowledgements}

The authors are grateful to scientists at the Malaysia Energy Centre, Flextronics (M) Sdn. Bhd., Silterra Malaysia Sdn.Bhd., and the Fachhochschule Esslingen-Hochschule für Technik for research collaborations.

\section{References}

Bergkessel N E et al 2000 US Patent No. 6,171,714

Kuendig J et al 2000 Thin-film silicon solar cells for space applications: radiation hardness and applications for an integrated solant (Solar cell-antenna) module, 28th IEEE PVSC, Anchorage, Alaska (IEEE Electron Device Society) Sallo J S 1985 US Patent No. 4,863,808

Wang W et al 2002 Improved triple-junction a-Si solar cells with heavily doped thin interface layers at the tunnel junctions, 29th IEEE PVSC (IEEE Electron Device Society) 